\title{
N $90-28442$
}

\section{Management of Information in a Research and Development Agency}

\author{
WALLACE O. KEENE*
}

A healthy scientific and technical information (STI) program is the result of objective implementation of effective and efficient processes for the production, dissemination, and utilization of information.

Objectivity is often at odds with policies promoted by those who do not distinguish between primary and secondary source information. If the primary database is not created and managed objectively, the research aided or influenced by that database will be biased. Control of selected information limits access to it and indirectly controls the research based on it. At risk are billions of dollars worth of research and the postponement or nonrealization of benefits that might otherwise result.

Effective and efficient management can require an identification of needs before determining the method of obtaining them. In this framework, a feedback mechanism is needed to help assess whether we are fulfilling the needs identified. This is an incredibly difficult but necessary undertaking that is often overlooked.

This section of the Government Information Quarterly provides an overall introduction to NASA's management of scientific and technical information, and it introduces the larger technological, managerial, educational, and legal frameworks in which NASA, as a federal agency, must transfer and disseminate information. The way NASA manages administrative information in support of its mission programs will also be discussed.

The issues to be addressed in the information arena over the next few years are significant. The management of information will affect the technological position held by the United States among the nations of the world. In 1989 the Office of Technology Assessment (OTA) stated that the health of the U.S. scientific and technological enterprise is critical to economic growth, quality of life, environmental protection, international competitiveness, and other national goals.'

*Direct all correspondence to: Wallace $O$. Keene, NASA Office of Management, Code NT, Washington, DC. 20546-0001.

Government Information Quarterly, Volume 7, Number 2, pages 127-140.

ISSN: 0740-624X. 


\section{WHAT IS SCIENTIFIC AND TECHNICAL INFORMATION?}

Federal STI is information developed as a result of scientific, technical, and related engineering research conducted or supported (e.g., inhouse or through grants or contracts) by the federal government. STI includes information from both basic and applied research in the entire range of scientific disciplines-physical, social, medical, terrestrial, and biological. Responses to regulatory functions, e.g., monitoring environmental health and safety, result in the collection of other federal STI.

STI is generated by almost all federal agencies to some degree, although most comes from five agencies-NASA, the Department of Commerce, the Department of Health and Human Services' National Library of Medicine, the Department of Defense, and the Department of Energy. Often, the documentation produced is the only physical evidence that research was done in the first place, and significant opportunities are likely to be missed unless we put the research results into the hands of others in a timely fashion.

For the past several decades, information has become the principal product of the federal government in the midst of what can only be described as a technological revolution. As a consequence, numerous laws and regulations have been imposed that focus on information and information-related resources. The following list identifies principal legislation affecting the overall management of federal information resources.

- The National Aeronautics and Space Act of 1958, as amended, P.L. 85-568, which requires NASA to make its research findings available to the maximum extent practical;

- The Paperwork Reduction Act of 1980, as amended, P.L. 96-511, which sets into place the framework for the management of federal information resources;

- The Freedom of Information Act of 1967, as amended, P.L. 90-23, which provides public access to federal government information;

- The Competition in Contracting Act of 1984, P.L. 98-369, which requires full and open competition in the acquisition of hardware and software with few exceptions;

- The Technology Transfer Act of 1986, P.L. 99-502, which encourages greater use of federally funded technology;

- The Export Administration Act of 1979, as amended, P.L. 96-72, which controls exports of equipment and technology that have both commercial and military usefulness; and

- The Arms Export Control Act of 1968, as amended, P.L. 90-629, which controls the export of military weaponry and services.

These laws, combined with diverse agency needs and other competing interests, have not always worked to the public's advantage. In the absence of any broad study on the matter, it is not possible to quantify any resulting loss or gain. Nevertheless, it is relatively clear that hundreds of millions of dollars worth of effort are at risk.

Part of our research funding is accounted for in the federal government's Information Technology Systems (ITS) budget for computer and telecommunications hardware, software, and services needed to process, distribute, and use scientific, technical, and administrative information and data. The ITS budget amounts to more than $\$ 18$ billion.

The U.S. aerospace industry dominates the world commercial aircraft market. As a result of the $\$ 17.7$ billion trade surplus it produced in 1988, aerospace replaced agriculture as the leading positive indicator in the U.S. balance of trade. It matters then, in this nation's interest, 
that research results and design information are properly released, released with a plan that provides new information first to U.S industry so that foreign interests cannot capitalize on the knowledge obtained at the expense of the U.S. taxpayers.

\section{IS THE IMPORTANCE OF STI A NEW PHENOMENON?}

Some believe that many of the STI issues are now emerging because of the evolution of information technology. Actually, the evolution of information-related technologies has only served to exacerbate the situation.

At a recent congressional hearing, Joseph Coyne noted that 25 years ago, the President's Science Advisory Committee (PSAC) recognized the importance of scientific and technical information and called for a review of the national STI structure.2 Despite the interest, improvements were not made relative to the structure, and a deterioration was perceived. In 1987, Representative Douglas Walgren again raised the issue:

Information with potential commercial value languishes inside [the] federal government because agencies do not aggressively seek a broader audience for its application. The Office of Science and Technology Policy, given a mandate by Congress to overcome these problems, has chosen not to exercise its authority. . . . The federal government has a unique role in the collection and dissemination of the best scientific and technical information from around the world, and our economy can ill afford further abdication of that responsibility.

Robert B. Reich recently observed that Japanese firms regard global scanning for technological insights as an integral part of their business strategies, but that most U.S. firms do not systematically gather data on the results of government-funded research (U.S. or foreign); nor do they systematically review technical and scientific journals and newspapers published in other countries. The U.S. government does little to aid them in such efforts. ${ }^{4}$

What's going on? We know the problem and we know at least part of the solution. OTA testified at the October 1989 congressional hearings that the main reason that the government lacks a comprehensive STI strategy is the failure to recognize the important linkages between STI and several national goals. STI is a critical link between R\&D and the achievement of other national goals such as improving the education of U.S. scientists, the strengthening of the U.S. civilian technology base, and fostering international cooperation on global problems. If left unattended, problems in managing and using STI will reach crisis proportions as the volume and complexity of STI continue to increase. . $^{5}$

The problem is not new and the fixes are not easy. Further, the implementation of solutions will have to take existing institutional mechanisms into account when winning strategies are being designed. The importance of the federal government's role in this enterprise, however, continues to be valid.

\section{THE IDEAL STI ENVIRONMENT}

The ideal STI environment would not be very complicated. Scientists and other researchers would have needed information available immediately. They could conduct further research and create new information. This new information would be immediately disseminated to peers and others for validation and then disseminated to the wider community. 
Changes in this synergistic research and engineering environment would be accommodated immediately by changes in the tools needed to facilitate the work being undertaken. For example, higher-performance workstations and increased storage capacity at reduced cost would be available, as would the necessary revised processing algorithms embedded in the computer program code.

It would seem that if you can describe what you want, it should be possible to obtain it. Unfortunately, it does not always work that way, and the key to understanding and managing such a situation rests with the need to approach the problem systematically and comprehensively.

\section{NASA'S STI-RELATED INFORMATION MANAGEMENT PROGRAMS}

NASA and its contractors generate STI at many sites and on many levels throughout the organizations. As illustrated in Figure 1, the basic mission elements of NASA can be stratified into three categories:

- activities that develop new knowledge-the Office of Space Science and Applications and the Office of Aeronautics and Space Technology;

- activities that facilitate the development of new knowledge and develop new knowledge as a result of their work-the Office of Space Station, the Office of Space Flight Operations, and the Office of Space Operations; and

- activities that use this knowledge to design and carry out new programs-the Office of Exploration and the Office of Space Science and Application.

Figure 1 identifies several other Headquarters organizations that have a role in NASA's overall program of information resources management. Most notably, these include the Office of Procurement (Code $\mathrm{H}$ ) and the Office of Safety, Reliability, Maintainability, and Quality Assurance (Code Q).

The NASA Office of Procurement governs how information resources are acquired contractually by NASA in line with the numerous regulations and policies imposed by external agencies such as the Office of Management and Budget (OMB) and General Services Administration (GSA). Often, it is the contract that brings together the diverse, and sometimes competing, technical, legal, and business interests of the government and the private sector. NASA technical managers rely on their procurement officials to assist them in acquiring and controlling contractor resources to implement NASA's scientific and engineering efforts. Given that the ratio of government to contractor staff at NASA is about 1:10 overall, procurement management is clearly an important factor in the management of NASA's scientific and technical information agenda.

The NASA Office of Safety, Reliability, Maintainability, and Quality Assurance is responsible for the independent assessment of these functions in all NASA's mission programs. Consequently, this office is the source of valuable engineering data about NASA's flight programs and the operation of the variety of telescopes, communications satellites, and other space orbiters deployed by NASA. Additionally, data elements on these efforts are germane to understanding the performance of the overall program in terms of national objectives, and therefore constitute a valuable input to executive information-related undertakings. 


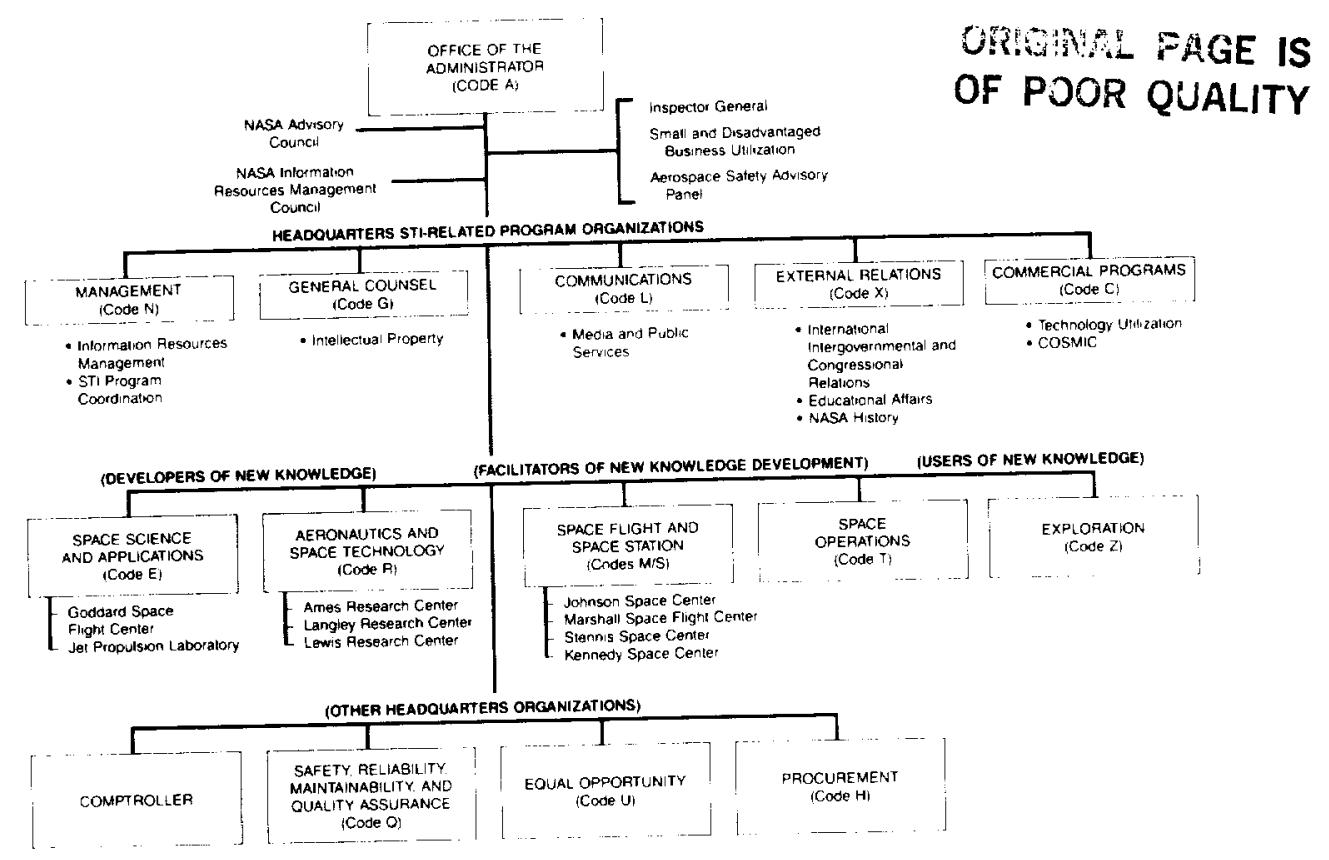

Figure 1. NASA Organization for STI.

It should be fairly clear that almost all NASA organizations can be viewed as involved in the production, dissemination, and management of STI, either directly or indirectly. NASA STI program interfaces are shown in Figure 2.

\section{RESEARCH EFFORTS SUPPORTING THE MANAGEMENT AND USE OF STI}

As an integral part of its space science and aeronautics research efforts, NASA has undertaken a Computer Science Research Program using advanced concepts in system architectures, algorithms, and software. The program is improving the state of knowledge of fundamental aerospace computing principles and is advancing computing technology in space applications such as software engineering and information extraction from data collected by scientific instruments in space.

Emphasis is being placed on producing highly reliable software for critical space applications and for managing the enormous volume of space data we expect to collect. Computers for Space Station Freedom alone may employ 30 million lines of computer code. In addition, as shown in Figure 3, the projected growth rate for space science data through the mid-1990s is significant.

The program also includes the development of special algorithms and techniques to exploit the computing power provided by high performance parallel processors and special purpose 
architectures. Critical areas needing these advancements are computational fluid dynamics, computational chemistry, structural analysis, signal processing, and image processing. Figure 4 provides an indication of the processing speeds attendant to the performance of specific types of scientific experiments. The computer architectures of interest include common and local memory multiprocessors, single-instruction-stream/multiple-data-stream processors, static data flow processors, systolic arrays, and heterogeneous multiprocessors with custom processors. Research is conducted in programming languages and environments, parallel and distributed operating systems, and performance measurements.
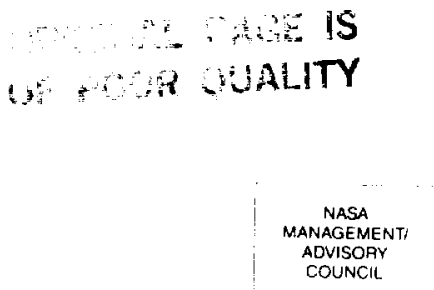

COUNCIL

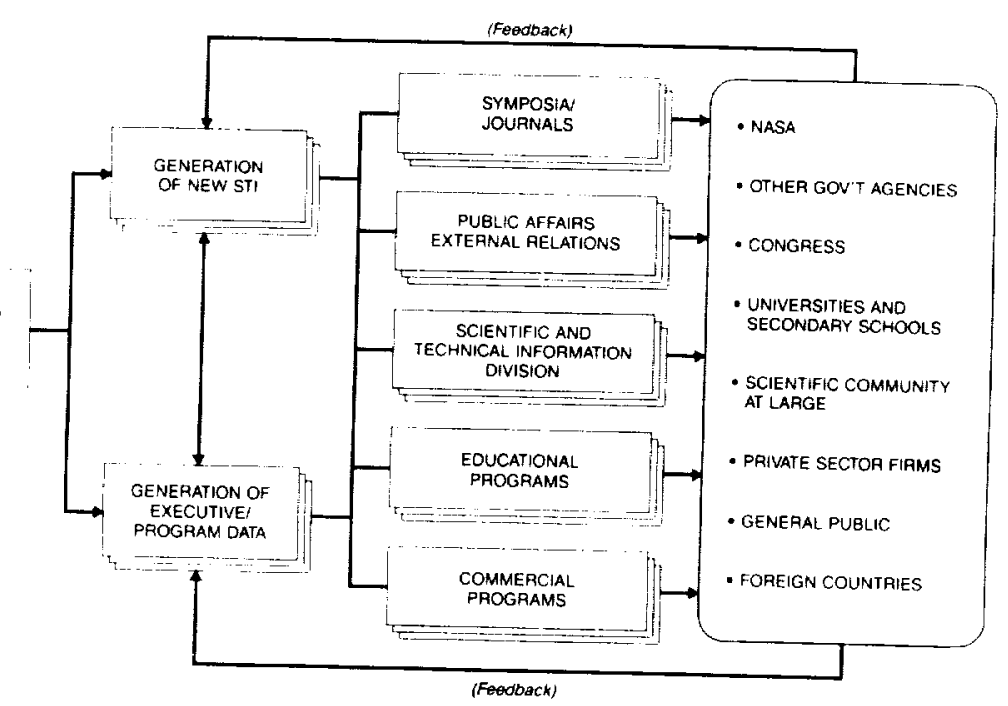

Figure 2. NASA's Scientific and Technical Information (STI) program interfaces.

NASA is conducting research in the fundamentals of database logic. This work has resulted in the development of a common user interface for accessing data from several databases with different structures. This work provides the foundation that will provide to NASA space data users access to multiple databases regardless of their physical distribution or structure. This work will reduce the cost of these information searches and will allow intensive research that would otherwise be unaffordable. Other work is under way to develop and test an expert system that can assist researchers to analyze data derived from space exploration.

NASA is conducting research to improve techniques for producing reliable computing systems. Its goals are to reduce the number of faults in software and to make fault-tolerant systems. New approaches and methods for software management and engineering have been devised and are now being evaluated under real working conditions. Future objectives for software engineering will include research on its theoretical foundation, and extending and evaluating approaches for developing reliable complex software.

This effort is coordinated within NASA through the Intercenter Planning Committee for Computer Science: representatives of all NASA installations and Space Station Freedom's Software Support Environment (SSE). It is coordinated externally with the Department of Defense (DOD) Software Engineering Institute, and by representation on the Federal 


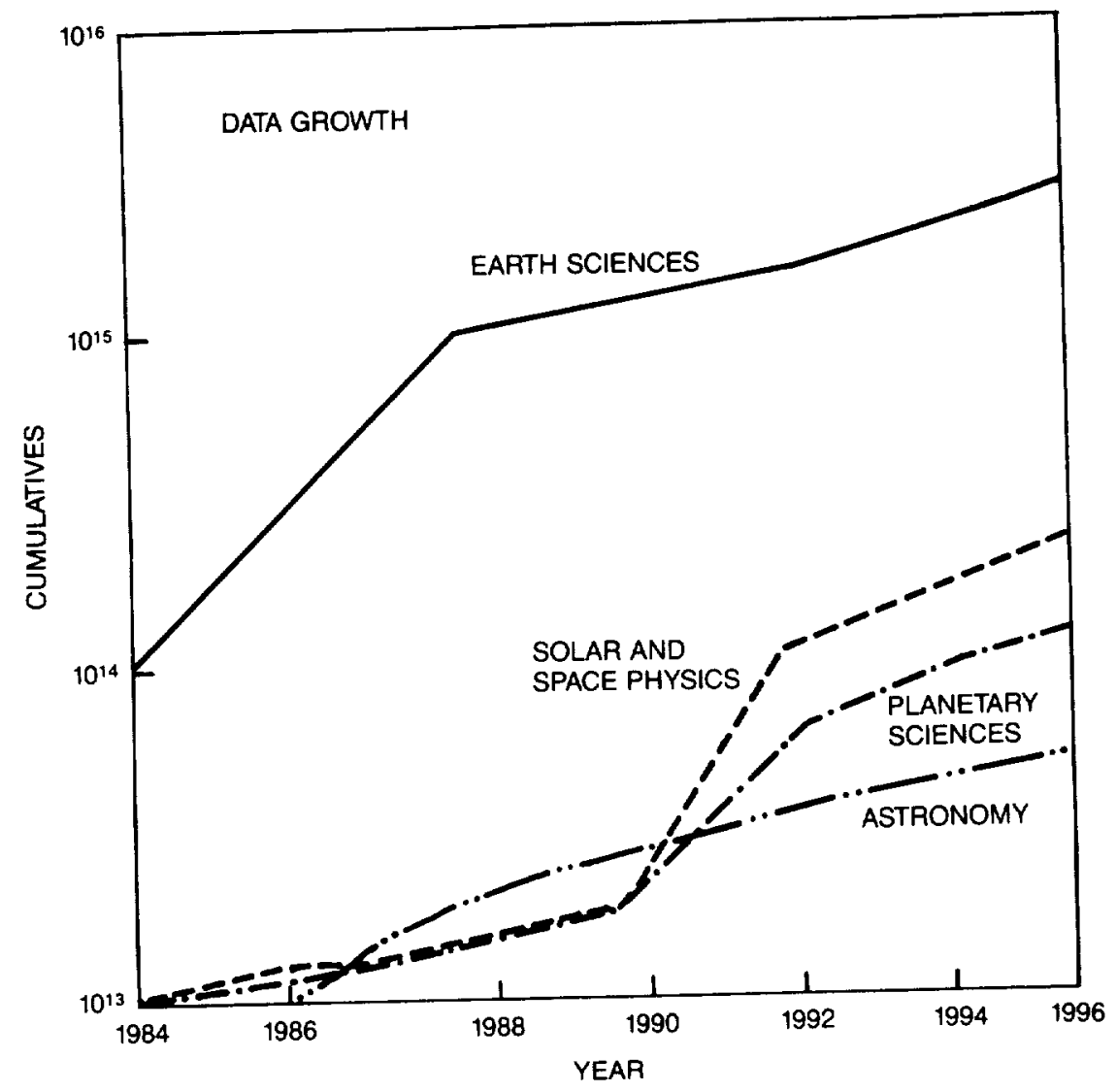

NOTE: Earth orbital missions assumed to last for 5 years, except for operational satellites and the space telescope, which are projected as continuing data producers

Figure 3. Projected Growth Rates for Space Science Data.

Coordinating Council for Science, Engineering, and Technology (FCCSET) under the auspices of the Office of Science and Technology Policy (OSTP).

NASA's High Performance Computing Initiative (HPCI) is a major topic of current legislation, which recognizes the tremendous importance of high performance to the United States' ability to maintain technical leadership in aeronautics, and to U.S. economic interests. In coordination with OSTP/FCCSET, the computation performance target for the HPCI program is a thousand-fold increase in performance within a 5-year period. The HPCI program will complement a variety of other NASA programs in the aerosciences, earth and space sciences, and exploration and experimentation. The program will directly complement the Numerical Aerodynamic Simulation Program.

HPCI's fundamental approach is to demonstrate to the aerospace industry the utility of advanced parallel computer systems capable of teraFLOPS performance. It develops and 
demonstrates a multidisciplinary simulation and design methodology to design new generations of high-performance aircraft and propulsion systems. Current trends in aerospace vehicle design require even more highly integrated vehicles and engines in which traditional, single-disciplinary analysis and optimization (e.g., aerodynamics, structures, controls) are no longer sufficient to achieve required performance goals. Future systems falling in this category include the National Aerospace Plane (hypersonic aircraft), high-speed civil transport, and transatmospheric vehicles.

\section{NASA'S ADMINISTRATIVE INFORMATION MANAGEMENT PROGRAM}

In 1984 NASA established the Automated Information Management (AIM) Program to improve the management of NASA by eliminating redundant automation efforts across common administrative functions and installing compatible hardware and software. Some 17 information systems are affected, including finances, personnel, information, and facilities and equipment. By standardizing the administrative information-processing environment, scarce personnel and dollar resources can be used to greatest advantage. The overall responsibility for the AIM program rests with the NASA Office of Management. Oversight and advice are provided by the AIM Council, composed of senior NASA executives. Specific projects, undertaken in response to user requirements, are delegated to individual NASA installations, with one installation being designated as lead. For example, development work on NASA's personnel and payroll system (scheduled for implementation in fiscal year 1990) was done by the Johnson Space Center.

AIM program work is undertaken in response to user requirements. A complete methodology (based on the Software Management and Assurance Program) has been developed and is shown in Figure 5.

Overall, the goals of the program are to:

-implement a coordinated set of agencywide automated administrative information system capabilities for optimum productivity improvements consistent with sound management and technical practice;

-achieve acceptance throughout NASA that information is a valued strategic resource that can increase effectiveness and efficiency in performing administrative and manage-
ment functions;

-optimize the interoperability of automated administrative information system resources, including the efficient exchange of information and transportability of software; and -optimize the effectiveness and efficiency in the management of designing, developing, and sustaining new agencywide automated administrative information systems.

In fiscal year 1989, the AIM program completed the initial phases of a review of management information needs throughout NASA. The results of this review will be the cornerstone of an appropriate data administration program to create the necessary administrative information architecture.

\section{COMMON INFRASTRUCTURE CONCERNS}

The discussion of the management of NASA's information programs would not be 


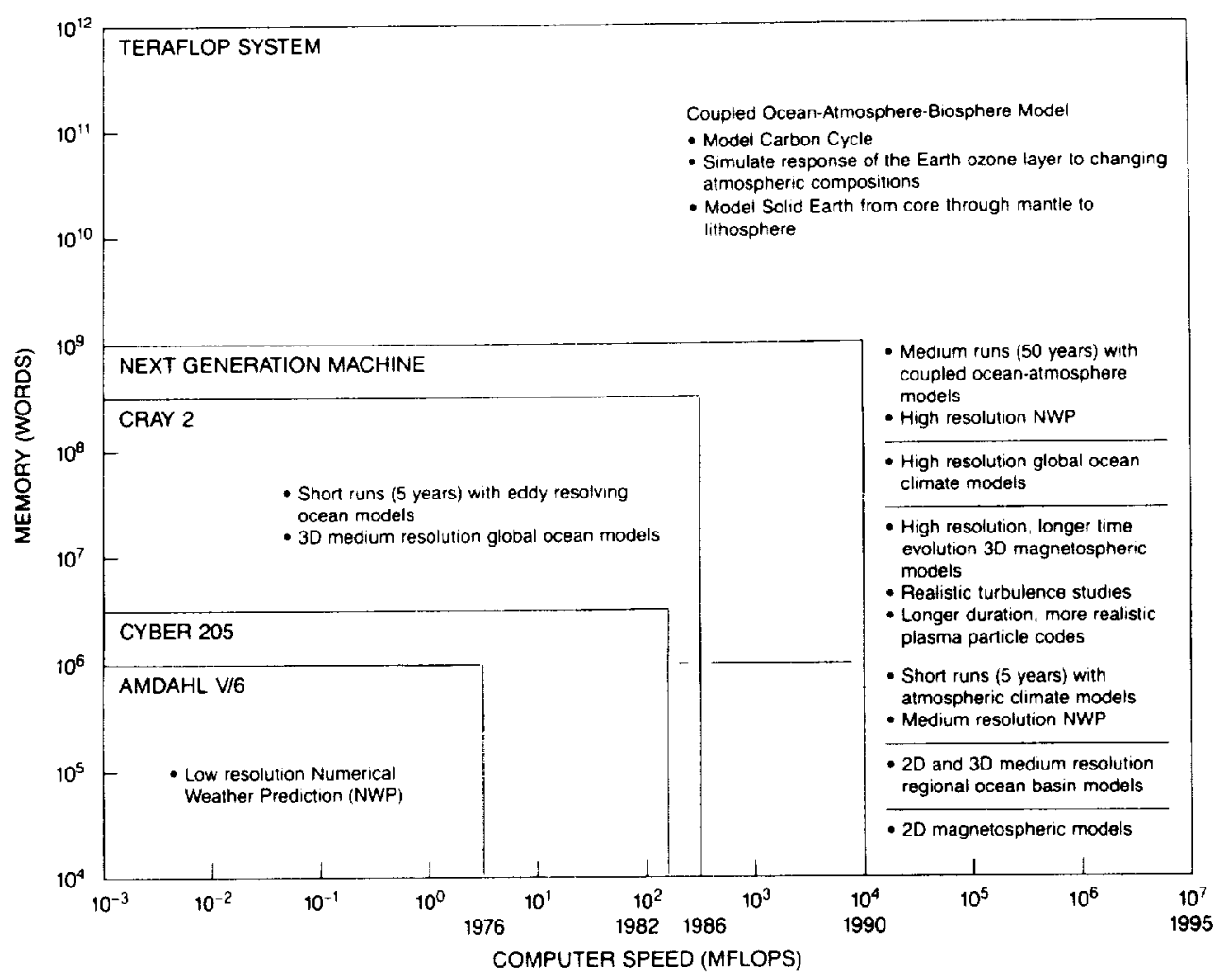

Figure 4. Modeling and Simulation of Space Science Processes Computer Speed and Memory Requirement.

complete without reference to the infrastructure necessary to manage the broad base of NASA information over its life cycle. The system often fails to respond effectively because the subject matter was not viewed systematically from the beginning. While the technological capabilities of individual NASA programs vary, a more broad-based, NASA wide approach is being formulated in line with evolving federal, national, and worldwide initiatives.

The principal technological factors affecting the management of information can be addressed at two levels. At the highest levels are architectures and standards that enable the components of the next level to interact appropriately. The next level consists of the computerand telecommunications-related hardware and software necessary to move data between users and to manipulate and store data.

NASA is fortunate to have an excellent telecommunications network, a critical component of its day-to-day mission operations. NASA researchers at the various NASA installations will increasingly work on joint projects, and additional loads will be placed on the system to link to local area networks and to facilities managed by contractors, universities, and consultants. Issues to be addressed will include those dealing with the federal 


\begin{tabular}{|c|c|c|}
\hline PHASE & DOCUMENTATION & REVIEWS \\
\hline - Predefinition & $\begin{array}{l}\text { - Project Requesı Document } \\
\text { - Feasibility and Cosi/Benefit Analysis }\end{array}$ & - AIM Council/HQ Reviews \\
\hline - Project Definition & $\begin{array}{l}\text { - Project Initiation Agreement } \\
\text { - System Concept Document } \\
\text { - Project, Configuration Management. and } \\
\text { Product Assurance Plan(s) } \\
\text { - Functional Requirements Document } \\
\text { - Procedures and Standard Manual }\end{array}$ & $\begin{array}{l}\text { - AlM Council/HQ Reviews } \\
\text { - System Requirements Review } \\
\text { with IPUC }\end{array}$ \\
\hline - System Development & $\begin{array}{l}\text { - Plan(s) Updates } \\
\text { - Requirements Specifications } \\
\text { - Design Specifications } \\
\text { - Test Plan and Procedures } \\
\text { - User and Operations Guides } \\
\text { - Training Plan }\end{array}$ & $\begin{array}{l}\text { - HQ Reviews } \\
\text { - Preliminary Design Review* } \\
\text { - Critical Design Review* } \\
\text { - Test Readiness Review* } \\
\text { ("means all with IPUC) }\end{array}$ \\
\hline - Implementation & $\begin{array}{l}\text { - Certification and Product Assurance } \\
\text { Reports } \\
\text { - Site Installation Plan } \\
\text { - Support Plan (for ongoing operations) }\end{array}$ & $\begin{array}{l}\text { - HQ Reviews } \\
\text { - Performance Demonstration } \\
\text { with IPUC } \\
\text { - Functional Configuration Audit } \\
\text { - Physical Configuration Audit }\end{array}$ \\
\hline
\end{tabular}

IPUC * INTERINSTALLATION FROJECT USER COMMITTEE

Figure 5. Summary of AIM Project Management Requirements.

government's new telecommunications system, FTS2000, as it comes into service, network security, and interoperability of local area networks with the NASA-wide telecommunications network.

The question of security is paramount, and there are a number of equally important issues addressed under such terms as internal controls, risk management, and vulnerability analysis. From a security standpoint, NASA serves three communities that have distinctly different security concerns reflected in their data-processing and telecommunications operations.

- The research community in which NASA interacts operates in an open environment that fosters the free exchange of ideas. Care has to be taken not to institute controls at odds with the basic purposes of the program.

- The manned space shuttle mission operations that NASA operates are unique to NASA and are tightly controlled.

- Research information obtained from DOD is governed by the policies of DOD and are controlled as required.

Once all telecommunications concerns are addressed, the computers can acquire and process data. This presumes, of course, that some accommodations have been made to resolve the dissimilarities, among the operating systems of micro-, mini-, and mainframe computers throughout NASA. The evolving standards for Open Systems Interconnect (OSI) must be implemented to make computer software applications and files portable among data-processing environments. (NASA employs both versions of UNIX as well as several other operating systems.) 
A further important consideration here may be the need to more closely integrate access to STI with the workstation environments of the researcher. This is both a technical issue and a human one. It is not clear that the researchers themselves would want to search and retrieve information. The Langley Research Center has implemented a pilot program that seems to work satisfactorily. Reference assistants are assigned to research organizations rather than having the researcher visit a reference library.

In some cases, the problem is not the dearth of information, but the oversupply. NASA's taxonomy of STI terms is an exhaustive three-volume thesaurus that forms the basis for its information retrieval process. ${ }^{6}$ While some preliminary assessment has been made regarding the use of Boolean logic-based screening programs, such is not yet a reality. Training is required to fully exploit the database as it expands to include the increasing volume of space-related scientific and engineering reports.

Last but not least are storage considerations. There is widespread interest in the use of Compact Disk Read-Only Memory (CD-ROM) evolving as the most cost-effective mechanism to provide compact, high-resolution data storage. NASA's programs encompass plans for an enormous amount of data-thousands of terabits. Fortunately, plans are already under way to identify and sponsor research in areas of computer science that might not be expected to evolve without some encouragement from NASA. Nevertheless, the future is still challenging because of the lack of universal standards.

Years ago when STI was not computer-dependent, the sharing of information might have been labor-intensive, but it was not technically difficult. However, this sharing often occurred in a largely monolithic environment where projects were relatively independent. The technology that has evolved over the years can handle large volumes of data efficiently. As this technology evolved, researchers saw new ways of approaching problems and integrating solutions. With new opportunities often come new risks, and continued thoughtful development is necessary to establish the overall infrastructure of NASA's information management systems. A recent MIT study pointed out that putting the new technology in place can impede progress, if choices are not thought out carefully, because expensive conversion costs, hardware and software replacement costs, and retraining costs may be incurred.

How does one deal with such a diverse set of parameters? Part of the answer has to do with leadership. In 1988 NASA established an Information Resources Management Council comprising NASA's top management team. Because of competing priorities and the numerous demands on NASA's key executives, the Council chose to focus initially on specific issues of high importance rather than to attempt to undertake a much broader initiative.

The wisdom of this approach has proven itself. Significant near-term gains are evident and information resource management plans are meshing with the more sweeping NASAwide strategic planning efforts. The Council has undertaken several important activities, including:

- reviewing NASA's software management practices and chartering the Ada and Software Management Assessment Group to provide a more comprehensive assessment;

- briefing Council members on selected NASA information resource-intensive projects that have the potential to affect other NASA areas, such as Space Station Freedom;

- briefing Council members on the direction being taken in this area by the U.S. Congress, GSA, and other central agencies, and the selected experiences of other agencies comparable to NASA in dealing with these organizations on information resource management issues, including system security; 
- reviewing organizational, financial, and other impediments to effective use of information resources;

- recommending raising the delegations of procurement authority of all NASA organizations from $\$ 1$ million to $\$ 2.5$ million to expedite acquisitions; and

- conducting a survey of NASA program and installation officials regarding the utility of existing standards and the need for new standards.

As early as 1964, NASA had an Intercenter Committee on ADP to coordinate informationtechnology-related matters. This committee continues to function, addressing the changing nature of the issues as the technology began to mature.

\section{EXTERNAL ORGANIZATIONAL INTERFACES}

In addition to technological considerations affecting the information management program infrastructure, there are numerous organizational interfaces that directly affect the ability of any federal agency to effectively manage its STI. These interfaces include:

- the Office of Science and Technology Policy, which establishes and coordinates policy matters of great national importance for those issues under its purview;

- the Office of Management and Budget, which must approve the funding for individual projects and institutional operations;

- the General Services Administration, which must approve all procurement actions for computer and telecommunications hardware and software above \$2.5 million (GSA will also control the implementation of FTS2000 and NASA's associated costs.);

- the National Archives and Records Administration, which is charged to collect information and make it available as a historic record;

- the Department of Commerce, National Institute of Standards and Technology (NIST), which must approve the use of new standards or variances from standards. NIST is also responsible for the security of sensitive (but unclassified) systems not under the purview of DOD;

- the National Security Agency, which is responsible for the security of classified systems and data under the purview of DOD;

- the congressional Joint Committee on Printing, which sets standards and control all contracts for printing of federal documents, including scientific and technical reports;

- the American Institute for Aeronautics and Astronautics (AIAA), which has been designated by the American National Standards Institute to establish the standards for space-science-related information; and

- the Advisory Group for Aerospace Research and Development (AGARD) of the North Atlantic Treaty Organization (NATO), which oversees the exchange and use of aerospace STI among NATO partners and between NATO members and non-NATO nations.

\section{LOOKING TO THE FUTURE}

The foregoing was designed to give visibility to the enormous administrative framework in which information managers must work to effect the transfer of knowledge resulting 
from NASA's research efforts. Despite the complexity, the framework is workable and the job does get done. In many cases, what is perceived as bureaucratic is part of the system of checks and balances necessary to ensure that the objectives of both public policy and scientific merit are being met.

Since Apollo 11 landed on the Moon more than 20 years ago, NASA has undergone significant change. During this period, staffing levels dropped from 45,000 to 22,000 . Comparable reductions in funding levels also occurred, although funding levels of the past few years have begun to increase in terms of constant dollars. Nevertheless, NASA is on an upswing and an important part of the rebuilding process is a new assessment of its STI Program to ensure that it responsibly meets the needs of the NASA community of scientists and engineers.

As mentioned earlier, evaluation is an important aspect of a well-managed program. Over the past several years, NASA has conducted a pilot survey of members of AIAA. While the findings are not conclusive (because AIAA is only one space science and engineering organization with membership from both the public and private sectors), 92 percent of the respondents indicated that NASA STI was important in terms of advancing the state of the art. ' While the survey results show reasonably good acceptance of the finished product, NASA needs to move ahead to tailor its automated delivery of the information as effectively as possible.

The Technology Transfer Act of 1986 prompted a broad range of concerns as well as opportunities. The potential now exists for NASA scientists and engineers to receive royalties from their patented and copyrighted material. Increased opportunities in this area may help NASA and other federal agencies to retain skilled researchers. This also means, however, that new incentives will have an additional impact on how STI is managed by federal agencies.

In a very farsighted move, the U.S. Congress directed OTA to review U.S. policies for the control and dissemination of STI. Among other things, OTA's report recommends that Congress needs to consider strengthening the role of the Office of Science and Technology Policy (OSTP), which is directed by the Science Advisor to the President of the United States.

NASA is preparing for its future of increasingly complex and fascinating exploration and discovery. The participants in, and the beneficiaries of, these efforts will be the American people, and, to varying degrees, all nations on Earth. We believe that the management of NASA's STI will play an important role, and there is much work to do to ensure that NASA's program is objective, effective, and efficient.

\section{ACKNOWLEDGMENT}

The assistance of the Office of Aeronautics, Exploration and Space Technology, and the Office of Space Science and Applications in assembling the information from which this section was prepared is greatly appreciated.

\section{NOTES AND REFERENCES}

1. Office of Technology Assessment. "Federal Scientific and Technical Information: Opportunities and Challenges of Electronic Dissemination" (Washington, D.C.: United States Congress, July 18, 1989), p. 128.

2. Joseph G. Coyne. Statement to the U.S. House of Representatives, Subcommittee on Science, Research and Technology, (October 12, 1989). 
3. Douglas Walgren. News Release: Hearings on Science and Technology Information Policies (Washington, DC: House Committee on Science, Space and Technology, Subcommittee on Science, Research and Technology, June 1987).

4. Robert B. Reich. "The Quiet Path to Technological Preeminence," Scientific American, (October 1989), p. 43.

5. Fred B. Wood. Statement to the U.S. House of Representatives, Subcommittee on Science, Research and Technology (October 12, 1989).

6. NASA Thesaurus. Volume 1: Hierarchical Listing; Volume 2: Access Vocabulary. Volume 3 Definitions. NASA SP-7051 (Washington, DC: NASA, 1988).

7. Thomas E. Pinelli and Myron Glassman. An Evaluation of Selected NASA Scientific and Technical Information Products: Results of a Pilot Study. NASA TM-101533 (January 1989). 